\title{
A Qualitative Exploration of Professionals' Perceptions on Entrepreneurial Intentions: A Case of Lecturers at a South African University
}

\author{
Ferdinand Niyimbanira \\ Lecturer in Economics \\ Faculty of Management Sciences \\ Vaal University of Technology \\ Private bag X021, Vanderbijpark, 1900 \\ Email: ferdinandn@vut.ac.za
}

\section{Doi:10.5901/mjss.2013.v4n6p315}

\section{Abstract}

A professional is a person who is paid to undertake a specialized set of tasks and to complete them for a fee or a salary. The traditional professions were architects, medical doctors, engineers, lawyers, and commissioned military officers. Today, the term is applied to accountants; artists; educators; librarians; nurses, scientists, technology experts, social workers, and many more. An inevitable reality is that not all full time employed professionals; young and old; are satisfied with their salaries. Some do leave their jobs to start their own business, others do combine both. Most literature reveal that the self-employed individuals are more satisfied with their jobs because their work provides more autonomy, flexibility, and skill utilization and greater job security. The current study adopts a qualitative approach using in-depth interviews to examine the perceptions of professionals towards entrepreneurship. Semi-structured in-depth interviews were conducted and recorded with 13 lecturers from one university in South Africa (Vaal University of Technology). An analysis of the transcripts yielded five themes, namely being risk averse or risk taker, time constraint and management, insufficient salary, family background and lack of financial support and resources. The results suggest that some professionals who are full time employed did take the opportunities to make extra income by embarking on their own business while others are still in need of support or need of being illuminated on what entrepreneurship is all about and its importance. Based on the findings of the study recommendations were made and further research is suggested.

Keywords: Entrepreneurship, Entrepreneurial intention, perception, Professional, South Africa

\section{Introduction}

Many entrepreneurs would love to focus entirely on their business, startup or idea, but is not always the case. Because there are many reasons and motives which drive one to become an entrepreneur. For example, some individuals became entrepreneurs because of circumstances around them are forcing them to become one; such as having a family, the pressure from parents to complete their studies, not to mention those who are working and find their salaries insufficient. These part time entrepreneurs juggle between studying, working part or full time, and running their business. They have 24-hours a day like any other individuals and their competitors. However, when running business part time; tasks may get delayed at work, the business may progress slowly as compared to competitors and the entrepreneur might get discouraged and give up on his/her dreams (Liew, 2012).

Entrepreneurs have good reason for working full time at a job and part time on their businesses. According to one of the expert in entrepreneurship; Paula Englis , quoted in Henricks (2009:1) said that "for some people, especially in economic times like these when they're worried about their regular job, starting a par time business gives them a safety net." She also added that "part-time startups by full time employees may also offer a source of extra income when future pay raises are likely to be infrequent or nonexistent." Hence, running a business while still employed can also make good business sense. An entrepreneur with a full time job to fall back on is under less pressure to make a venture succeed quickly." One may say that numerous issues still remain to be investigated in the field of entrepreneurship. Therefore, exploring the perceptions of professional workers is anticipating that the findings could result in recommendations that will assist in creating more opportunities which will help them to earn extra income apart from the one earned from their full-time job. 


\section{Motivation: Problem Statement and Research Gap}

There has been extensive theoretical and empirical research on entrepreneurship in both contexts of developed and developing countries. It is of imperative nature to understand that an entrepreneur has the spirit that is characterized by their vision, initiative, persistence and personal drive. Bissessar (2005) further indicates that the qualities needed for an individual to be an entrepreneur are: commitment to work and being a good leader, having creativity and being goal oriented, self confidence and willingness to take risks. The question is: most professionals do have some if not all of these qualities but what makes some to run their own business part-time while employed full-time and others don't. Despite the apparent awareness of the benefits associated with owning business, many professionals who are employed full-time have little intention of starting their own business, other do not have any at all. Entrepreneurial initiatives need to be encouraged because they lead to an increase of economic activities leading to economic growth later on. Little research has been done on this problem, especially in South Africa and on lecturers in particular.

\section{Purpose of Study}

An inevitable reality is that not all employed professionals; young and old; are satisfied with their salaries. Some do leave their jobs to start their own business, others do combine both. Most literature reveal that the self-employed individuals are more satisfied with their jobs because owning a business provides more autonomy, flexibility, and skill utilization and greater job security. The purpose of this paper is to find out the entrepreneurial intentions of full time professionals in South Africa focusing on lecturers and make recommendations on the findings.

\section{Research Objectives}

\subsection{Theoretical objectives}

Entrepreneurs require high levels of intelligence that is enough to gather and interpret large amounts of information. Good entrepreneurs need to possess the ability of creating visions, solving problem and making correct decisions (Greenberg et al 2001: 10). This is a true indication that professionals assumed to have all these, including commitment and leadership qualities which build trusting relationships between themselves and customers by being truthful and non deceitful and by showing high consistency between word and deed in business. Good entrepreneurs are always motivated and they do not resist change. This means, full time employed individuals can take up the entrepreneurial initiatives regardless time constraint they may have. Hence, this paper tried to find out:

- Who are professionals and entrepreneurs in same time

- What may make an individual to be both full-time professional and entrepreneur part-time

- Possibility of starting a business when you are full-time employed

\subsection{Empirical objectives}

There is a lot of literature on entrepreneurship (See Greenberg et al 2001; Bissessar, 2005 to mention few). However, the literature on the entrepreneurial intentions of full time professionals in South Africa is scanty and on lecturers in particular. Therefore, the empirical objectives of this paper are to find out:

- Why full time professionals may start a business on a part time basis.

- What hinders full time professionals from starting part time businesses

- Challenges faced by full time professionals running businesses on part time basis

\section{Literature Review on who is an Entrepreneur}

On one hand an entrepreneur is an individual who possesses the ability to create employment not only for themselves but for the unemployed too (Bissessar, 2005). On the other, a professional is a person who is paid to undertake a specialized set of tasks and to complete them for a fee or a salary. The traditional professions were doctors, engineers, lawyers, architects and commissioned military officers. Today, the term is applied to nurses, accountants, educators, scientists, technology experts, social workers, artists, librarians and many more. Due to different motives, full time employed individuals may have also a part time business and both will need his/her attention and commitment. Farrell 
(2000) states that commitment "comes from the heart and produces an abundance of pride, loyalty and plain old hard work." Individuals who establish their own businesses need not to deviate from the four vital practices which include: loving what they do, giving autonomy, demand accountability, share fortune and misfortune. Being good entrepreneur requires leading by example and devotes both financial and human capital to the venture. Dagoon et al (2005) indicates that a good entrepreneur demand quality and efficiency not only from their employees and suppliers but also from themselves. Commitment to work clearly underlines that entrepreneurs must lead and set examples of excellence thus simultaneously motivate employees to follow and execute the corporate strategy by providing customers with high quality products or services.

Entrepreneurship requires both capability and commitment. The success of an entrepreneur is determined by the quality of his/her leadership. The study of Robbins and Coulter (2007) reflect that a good leader exhibits high effort levels. Good leaders have high desires for achievement. This shows their level of ambition and commitment in the nature of implementation in their activities showing initiative. Entrepreneurs have strong desires to influence and lead others, demonstrating willingness to take responsibility (Swanson and Holton, 2009).

Good entrepreneurs need to have the proper knowledge, skills and abilities in the formulation of the organisation. This includes the organisational structure and organisational culture. Obviously, organisational structure assists for employer and employee to understand the flow of communication and managerial roles within the organisation. Organisations that usually operate off a decentralized structure often have high commitment in work (Tyson and York, 2000, p. 129). This is created because employees are given the platform to share their ideas and promotes team orientation with specific divisions. Teams allow for shared tasks and multi-tasking. This allows for employees to share knowledge, skills and ability thus enhances work diversity and increases the level of motivation between employer and employees (Hofstede 1991:32).

The work of Kuratko (2007) indicates that being an entrepreneur requires combination of both imagination and creative thinking; this however should encompass systematic and logical process ability which intellectuals and scholars have. The combination of imaginative and creative thinking allows for entrepreneurs to create successful innovative products and services for the business. A good entrepreneur needs to find ways to fill gaps in society thus fulfilling customer needs and wants. Gaps in society reflect that there are problem areas that entrepreneurs need to recognise thus find ways in solving the problem. The overall vision is to create solutions and simultaneously creating opportunities for the business that will best differentiate products and services from competitors (Boddy, 2005 p.120). Therefore, one may assume that all said above should be easy for an academic professional.

For Kuratko (2007) creativity has two vital aspects which are process and people. People are the mechanism employed in to determine the solution. It is important to, however, understand that processes remain constant but the implementation may vary. Entrepreneurs also require using creative problem solving techniques. The techniques in this case are adaptor or innovator. Adaptors are individuals that use methodological approaches in problem solving. Their objective is to solve problems rather than identifying problem areas that need problem solving. Their character is more on the reactionary formation. This can be clearly defined with the fact that they prefer refining current practices thus enhancing a conservative image. The innovator unlike its counterpart discovers problems and finds solutions with the aid of different calculated approaches. The nature of an innovator does not allow for them to tolerate routine work. Innovators best define creativity as a process that can be developed and also improved with time (Phillips, 2005 p.20).

According to Kent (1990) entrepreneurship requires being goal oriented. Goals are measured with the level of one's motivation and their desire to achieve accomplishments. The nature of accomplishment creates a working environment that enhances the learning curve allowing for the individual to venture into different business avenues. Entrepreneurs need to clearly define their goals. There are two ways in goal setting which are short and long term goal orientations. Emerging entrepreneurs are often met with temporary defeat arising from the inability to clearly define their goals. This pitfall is caused by the little experience they possess. It is also important to note that pitfalls of this nature can be changed with intensive research, investigation, planning, leading and controlling (Armstrong and Kotler, 2006).

Goal orientation leads to the formulation of strategies and tactics with an objective of accomplishing the overall purpose of the entrepreneur (Tanner et al., 2009). The major aim of the goal is to set the tone to the mission of the business. Good entrepreneurs use the marketing planning process in the achievement of competitive strategies. This includes analysing the current external and internal situation, researching and analysing markets and customers, determining segmentation, targeting and positioning, set marketing plan objectives and direction, planning marketing strategies, programmes and support, plan to measure progress and performance and implement, control and evaluate plan. The overall vision of marketing planning is to assist the entrepreneur in achieving his/her business objectives and expand it. Expanding business includes exploiting current markets, adding new markets, offering existing products, 
modifying existing products and offering entirely new products. It is important for entrepreneurs to be goal oriented in order to employ growth strategies to their organisation (Armstrong and Kotler 2006).

Daniels et al (2009) indicate that in the process of achieving goals and objectives, knowledge, skills, abilities and self confidence is needed to effectively execute the corporate strategy. In order to achieve self confidence, entrepreneurs should have positive mind sets that are goal oriented. Lack of self confidence reduces the chances of success within the business. The reason for this is that the entrepreneur will fail in providing leadership and motivation to employees. Having a low self confidence often arises from the fear of criticism. Entrepreneurs that are confident possess creative and imaginative thinking and analytical abilities. Entrepreneurs that are confident enhance organisational performance through employee effectiveness. An organisation that operates with a high degree of confidence allows for relationships to be build with external stakeholders. Change is constant thus change always changes. This means that whatever change that occurs in the external environment will simultaneously affect internal business processes. Entrepreneurs and employees that are self confidence possess high levels of motivation thus are able to create effective strategies for the organisation to adapt to change. Organisations that are able to adapt to change are flexible in nature and are able to take part in the hyper competitive environment (Sengupta and Bhattacharya, 2006).

Self confidence is achieved by a degree of learning, education, training and development. The reason for this is because like culture self confidence is taught thus does not gain the title of genetic (Muendane 2006: 147). It could be said that self confidence is a stereotype based on the fact that is influenced by ones state of mind. Entrepreneurs can build their self confidence through auto suggestive thinking. This however will develop and improve the state of mind through the repetition of positive thought. Mallows hierarchy of need theory best defines self confidence because individuals need to attain physiological, security, social, esteem needs in order to achieve the state of self actualization which is also known as self mastery or better yet self confidence (Robbins and Coulter, 2007)

The problem with uncalculated risks is the manner in conducting business within the hyper competitive environment. Conducting business on chance creates more external threats rather than opportunities and more internal weaknesses than strengths. Organizations that operate on this degree are often met with failure (Wood 2004: 101). Calculated Risks allow entrepreneurs to formulate effective strategies and tactics for their businesses survival in the competitive environment. This allows entrepreneurs to gather both primary and secondary research thus enhancing their knowledge on the type of environment where business operations shall take place (Bove'e and Thill 2008). Entrepreneurs need to understand the changing environmental trends. These trends include politics, economy, socio culture, technology, environment and legislature. These factors influence the nature in which business operations shall take place. Once there is a clear understanding of the external factor, entrepreneurs require to conduct an industry analysis. The reason for this is to analyse the nature of competition and the barriers to entering the particular market. It should be emphasised that a country that was established by capitalism shall operate off a specific level of capitalist principles. The growth of technology has expended the capitalist trait thus creating a global market. Globalisation has exposed people to wide range of needs, wants, change in tastes and demands. With calculated risks entrepreneurs gain an advantage to achieving competitive advantage or making profits by understanding marketing principles (Tanner et al. 2009).

\section{Methodology}

Qualitative approach which was based on a comprehensive literature study was adopted to extend the small body of literature on professionals' perceptions on entrepreneurship. According to Patton (2002) the aim of qualitative research is to explore real life world of interviewees and obtain an insider perspective of the phenomenon being studied on. For Sooful, Surujlal and Dhurup (2010) quantitative method combined with semi-structured questions and probing during telephonic interviews allowed for collection of data in the respondents' own words, rather than limiting them to select from fixed responses required in a quantitative method. This study used telephone and face-to-face interviews.

Purposive sampling as suggested by Merriam (1998) was employed in this study which was assumed that individuals chosen for the study would be those who will provide most valuable information which would help to discover, understand and offer relevant insights of the phenomenon being studied. The professionals were thirteen lecturers from Vaal University of Technology, Vanderbijlpark Campus, South Africa.

Explanation regarding the objectives and purpose of the study was given to all participants before interview took place. Assurance of confidentiality was given the reason why anonymity was used in this paper. Lastly, participation was voluntary and participants could terminate interview at any stage. After these explanations, interviews were requested to be recorded and recordings were transcribed verbatim by the author. 


\subsection{Reliability and Trustworthiness}

Credibility checks was used to ensure the trustworthiness of the results. The researcher examined all transcripts and analysed the data. Five participants were provided with their interview transcripts to double check if their data were correctly captured as proposed by Lincoln and Guba (1985) that reliability could be ascertained using member validation. These participants gave the feedback indicating that data were an accurate reflection of their interviews.

\subsection{Data analysis}

Analysis of the demographic data indicate that respondent were 13 ( 5 females and 8 males), 4 were white and 9 blacks and all were below 50 years of age. In terms of experience in their profession of lecturing it was between 3 and 25 years. Respondents were from different field such as management sciences (7), engineering (4) and Mathematics (2). Regarding the positions 4 were junior lecturers, 6 lecturers, 2 senior lecturers and 1 associate professor. On one hand, some of participants (7) showed no entrepreneurial intention at all even though all had an idea of importance of earning extra income via owning business. On the other hand, some lecturers $(n=3)$ had a wish to own a business in near future and had idea of which type of business will be. Only 3 respondents indicated that they own businesses. According to the writings of Gustafsson et al (2008) who opined that description and interpretation are very closely related in qualitative research. Hence, an analysis of the transcripts yielded numerous similar statements which were subsequently grouped into the following themes: being risk averse or risk taker, time constraint and time management, insufficient salary, family background and lack of financial support; resources and skills are discussed in the following section.

\section{Results and Discussion}

\subsection{Risk aversion versus risk taking}

Risk aversion is defined as "the reluctance of a person to accept a bargain with an uncertain payoff rather than another bargain with a more certain, but possibly lower, expected payoff" (Wikipedia, 2012) while risk taking or risk loving is the willingness to engage in fair games or businesses but also challenging. Entrepreneurs should be able to be risk takers (Tanner et al. 2009). The core aim and objective of establishing a business is to make a degree of profit by exploiting markets, producers and attracting customers. Risk comes in two forms calculated and uncalculated. Uncalculated risks can be defined as probability. This is because the less planning, organising, leading and controlling was taken in the formulation of the business. Majority of those who participated in the study showed that are in the category of risk aversion. Meaning, probably they require a higher expected rate of return to hold a security that has an uncertainty payoff than they do to hold a security paying a certain return. However, there are few who show that they have businesses which are changing their lives more positively and are happy with the experience so far.

\subsection{Time constraint and time management}

Balancing a career while owning a business isn't easy but it can be done and many people have been doing it. However, some do find it very difficult to manage both due to limited time. For example, a person working full time might not be able to manage his/her business because they will not have enough time to run the business as most of time will be taken by their full time work. Having a full time job and business part time may cause a lot of workload and may result in not meeting the deadline required by employer. Hence, when one venture on part time business, the issue of time management is very crucial and needs to be taken in consideration.

\subsection{Insufficient salary}

Some studies has shown that levels of self-employment in many countries are increasing, and that under certain circumstances this can have positive effects on per capita income and job creation which is very good for the economy of any country. On one hand, many participants may wish to have their own business because what they are earning currently is not sufficient. On the other hand, a person who has insufficient income it will be difficult for him/her to save for sufficient capital and in the same time it wouldn't be easy to get a loan from the bank since getting a loan requires one to meet some minimum requirements including sufficient income. 


\subsection{Family background}

It is believed that being born in family which has business may have influence on decision of starting own business. However, this study discovered that, participants were not influenced by their family background. This may be caused by the intellectual level and capacity. In other words, family background has influence to certain extend not always.

\subsection{Lack of Financial support, resources and skills}

This study found that some participants do want to start their own business but they do not have enough financial support such as accessing bank loan and other resources (i.e. land, entrepreneurship skills) which are part of factors of production. In South Africa, is clear and crucial issue which need to be addressed and this paper suggest that policymakers might want to exercise more caution in implementing policies that have adverse effect on small business in general, including those which are owned by full time professionals in particular.

Table 1. Issues, description and excerpts from in-depth Interviews

\begin{tabular}{|c|c|}
\hline Issues and description & Excerpts from in-depth interviews \\
\hline $\begin{array}{l}\text { Being risk averse/Being } \\
\text { risk taker }\end{array}$ & $\begin{array}{l}\text { - "Not interested to start own business" } \\
\text { - } \quad \text { "I do have idea of which type of business I want to open but } \\
\text { procrastination is a problem." } \\
\text { - "Mixing part-time self employment and full-time employment achieves } \\
\text { nothing" } \\
\text { - " " already have a business and is growing well." } \\
-\quad \text { "One may not be able to balance the two." } \\
\text { - "Some employees have a way of "stealing" from employer if they are left } \\
\text { alone. Proper supervision cannot be done if employed full-time and } \\
\text { decide to set up a business. Therefore, I will end up not making enough } \\
\text { profit as expected." } \\
\text { "I have never been interested in business, I enjoy my chosen field; I am } \\
\text { also not aware of how one can start a business." } \\
\text { "When you start a business, if proper care is not taken, staff members } \\
\text { you leave the business with, eventually liquidate the business." }\end{array}$ \\
\hline $\begin{array}{l}\text { Time constraint and time } \\
\text { management }\end{array}$ & $\begin{array}{l}\text { - "I terminated my private practice because of the demand of my full-time } \\
\text { employment at VUT." } \\
\text { - } \\
\text { - I don't think I will have enough time to run my business." } \\
\text { "Usually I spend about } 2 \text { hours a day for business and the rest of the time } \\
\text { is dedicated to my full employment, on the weekends and holidays more } \\
\text { time is dedicated towards business." } \\
\text {-...but it comes with a price of not having enough time for yourself and } \\
\text { family. One needs to weight the relationship between family time and } \\
\text { financial stability." } \\
\text { "Time is not always available because academic work is very hectic. You } \\
\text { always have to work from home by setting tests and exam papers, } \\
\text { marking etc... and we have a high volume of students." } \\
\text { "The time schedule for my full-time employment is not flexible, hence is } \\
\text { very detrimental towards the commencement of my self-employment." } \\
\text {-Time is not an issue I can create time to do what I want." }\end{array}$ \\
\hline Insufficient salary & $\begin{array}{l}\text { - " " opened my business because it gives me an extra income." } \\
\text { - } \quad \text { " always think of starting my own business to supplement my income." } \\
\text { - "My business is for ensuring that I have a sustainable source of income at } \\
\text { the time of retirement." } \\
\text { - "Stating my own business could be the best in order to meet all my family } \\
\text { financial needs." } \\
\text { - "I would love to have a part-time business to supplement the heavily taxed } \\
\text { - } \quad \text { salary that I get." } \\
\text { "To earn an extra cash in order to supplement my current financial } \\
\text { commitment }\end{array}$ \\
\hline
\end{tabular}




\begin{tabular}{|c|c|}
\hline & $\begin{array}{l}\text { - } \quad \text { Always thinking of starting something so as to earn extra income but I am } \\
\text { still looking for an opportunity for me to start." } \\
\text { - It is always important to have another source of income because such } \\
\text { income supplements the salary. Salary never been enough to meet all my } \\
\text { demands." }\end{array}$ \\
\hline Family background & $\begin{array}{l}\text { - "My father had a business and I used to help him, but I don't see myself } \\
\text { as business person: I love lecturing." } \\
\text { - "No, the family background is not an issue." } \\
\text { - } \quad \text { "What made me to start my own business is an extra knowledge gained } \\
\text { as an academic in business management. I didn't learn it from my family" } \\
\text { - "No, as intellectual my family background has no influence in my decision } \\
\text { making." } \\
\text { - "Not at all!" }\end{array}$ \\
\hline $\begin{array}{l}\text { Lack of financial support, } \\
\text { resources and Skills }\end{array}$ & $\begin{array}{l}\text { - "Unfortunately, the capital to start the type of business that I would like to } \\
\text { - } \quad \text { " " need fin thancial support and, time and business management skills." } \\
\text { - } \quad \text { "If VUT would allow professional staff to apply their knowledge in a } \\
\text { practice in order to earn an additional income, it could help." } \\
\text { - "Lack of entrepreneurial skills." } \\
\text { - "I do not have enough capital to start my own business." } \\
\text { - "I Know it's possible for a lecturer to start their own business, the only } \\
\text { problem is support." }\end{array}$ \\
\hline
\end{tabular}

\section{Limitations and Implication for Further Research}

A limitation of this study is that data were collected from a small sample size, therefore; its findings should not be generalised. However, its specific contribution is that it adds to the body of knowledge on entrepreneurship among professionals and lecturers in particular. The issue of adopting entrepreneurship or becoming entrepreneur, particularly in the context of professionals in South Africa, is underdeveloped and thus calls for further exploration. The results of this study have implications for further research. This could be done if one investigates this issue with a larger group of participants using a quantitative method. It will also be interesting to conduct the study across different professionals to establish common trends and differences.

\section{Conclusion and Recommendations}

This study investigated the perception of professionals on entrepreneurial intention. It is evident that most young and old professionals in South Africa do have business in their minds but some reasons are given as why they do not start their own business apart from their normal job even though their salaries are not that enough. It is therefore, important for professionals to be assisted on how they can start their own business which is one of the key ways to fight unemployment and towards economic development. These supports could be communicative and financial ones which could be offered by employers, Government and non-governmental organisations by:

- Conducting needed workshops for those who do not have entrepreneurial, time and business management skills,

- Having an agreement with financial institutions such as banks to grant loan to intellectuals who wish to start their own businesses

- Conducting workshops which teach intellectuals importance of entrepreneurship for the development of a country

- Including entrepreneurship programmes in the education system

All the above might also decrease the employees' turnover which caused by looking for more job satisfaction.

\section{References}

Armstrong, G. \& Kotler, P., (2006). Marketing: An Introduction. New Jersey: Prentice Hall. 
Armstrong, M., (2003). A Handbook of Human Resource Management Practice: Fully Updated to Reflect Current Thinking, Practice and Research. London: Kogan Page Publishers.

Bissessar, R., (2005). Spirit of Youth: empowering a new generation. USA: Trafford Publishing.

Boddy, D., (2005). Management: An Introduction. 3rd ed. England: Prentice Hall.

Bove'e, C.L. \& Thill, J.V., (2008). Business Communication Today. 8th ed. U.S.A: Prentice Hall.

Dagoon, J.L. Dagoon, A. L. Dagoon, D. J. \& Mortola, R. G., (2005). Home Economics Technology. Manila: Rex Book Store, Inc.

Daniels, D. J. Radebough, L. H \& Sullivan, P. D., (2009). International Business Environments and Operations. New Jersey: Prentice Hall.

Farrell, R. S., (2000). A Yen for Real Estate: Japanese real estate investment abroad- from boom to bust. UK: Biddles Ltd.

Greenberg, J., R.; Baron, C. Sales \& Owen, F., (2001). Behaviour in Organizations. 2nd Canadian ed. Scarborough, Prentice Hall.

Gustafsson, H. Hassemen, P., Kentta, G. \& Johansson, M. (2008) a Qualitative Analysis of Burnout in Elite Swedish Athletes. Psychology of Sport and Exercise, 9(6), 800-816.

Henricks, M. (2009). You Don't Have to Quit Your Day Job: For many, the pros outweigh the cons when it comes to starting a business while still employed. [online] Available at: http://www.entrepreneur.com/article/200604 (12 March 2013).

Hofstede, G., (1991). Culture and Organisation: Software of the mind. London: McGraw-Hill.

Kent, C. A., (1990). Entrepreneurship Education: current developments, future directions. USA: Quorum Books.

Kuratko, D. F., (2007). Corporate Entrepreneurship. USA: Now Publishers Inc.

Liew, W. (2012). 15 Tips to Become a Successful Part Time Entrepreneur [online] available on: http://www.sproutgeek.com/successfulpart-time-entrepreneur/\#ixzz2KzHGj9fc (12 March 2013).

Lincoln, Y. S. \& Guba, E. G. (1985). Naturalistic Inquiry. Newbury Park, CA: SAGE.

Lincoln, Y.S \& Guba, E. G. (1985). Naturalistic inquiry. In Denzin, N.k. \& Lincoln, Y. S. (Eds.), Handbook of Qualitative research. Thousand OAKS: Sage.

Merriam, S. B. (1998). Quality Research and Case Study Applications in Education. San Fransisco: Jossey-Bass Publishers.

Muendane, N.M., (2006). I'm an African. South Africa, Soul Talk.

Paton, M. Q. (2002) Qualitative Research and Evaluation Methods. 3rd Ed., Thousand Oak, CA: SAGE.

Phillips, J. J., (2005). Investing in Your Company's Human Capital: Strategies to Avoid Spending Too Little or Too Much. Broadway: AMACOM Div American Mgmt Assn.

Robins, S. P. \& Coulter, M., (2007). Management. New Jersey: Prentice Hall.

Sengupta, N. \& Bhattacharya, M.S., (2006). Managing Change in Organizations. New Delhi: Prentice hall of India private. Ltd.

Sooful, J. A., Surujlal, J. \& Dhurup, M. (2010). Dance and Music as Medium for the social Integration of Children with Intellectual Disabilities into Mainstream Society. African Journal for Phyisical Health Education, Recreation and Dance, 16(4), 681-697.

Swanson, R. A. \& Holton, E. F., (2009). Foundations of Human Resource Development. 2nd ed. USA: Berrett-Koehler Publishers.

Tanner, J. F.; Honeycutt, E.D. \& Erffmeyer, R.C., (2009). Sales Management Shaping Future Sales Leaders. New Jersey: Prentice Hall. Tyson, S. \& York, A., (2000). Essentials of HRM. New York: Elsevier.

Wikepedea (2012). Risk Aversion. [Online] available at: https://en.wikipedia.org/wiki/Risk_aversion. (15 April 2013).

Wood, M.B., (2004). Marketing Planning Principles into Practice. London: Prentice Hall. 